\title{
Methodology for optimizing constrained 3-dimensional railway alignments in mountainous terrain
}

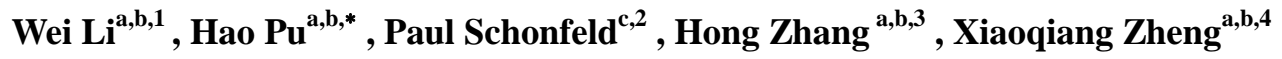 \\ a. College of Civil Engineering, Central South University, Changsha 410075, China \\ b. National Engineering Laboratory for High Speed Railway Construction, Changsha 410075, China \\ c. Department of Civil Engineering, University of Maryland, College Park, College Park, MD 20742, United States
}

\begin{abstract}
Railway alignment design is complex and time-consuming, especially for mountainous areas where the natural terrain gradient between the start and end points greatly exceeds the maximum allowed design gradient. Existing methodologies can optimize routes in areas with relatively simple topography, but often fail in finding the feasible alternatives in complex mountainous terrain. Thus, a two-phase methodology is proposed for optimizing multi-constrained 3-dimensional railway alignments. We generate various promising paths in the first phase and refine them into final alignments by fitting the required curved sections in the next phase.

Firstly, the study area is represented using a 3-dimensional rectangular lattice and a comprehensive geographic information model is specified to store and manage the geographic information in this lattice. Secondly, an objective function is developed for estimating the railway alignment's comprehensive cost. Thirdly, a multi-constrained distance transform is employed as a new approach for generating optimizing paths through various cells in the lattice. Multiple constraints on geometry, structures and locations are handled in this approach. To avoid possible failures in finding paths in the complex mountain regions due to multiple constraints, an adaptive neighboring mask and a bidirectional scanning strategy are proposed for generating various promising 3-dimensional paths. In the alignment fitting process we form the initial alignment by recursively inserting points of intersection and then optimize the final alignment using the mesh adaptive direct search algorithm.

The effectiveness of the approach is verified through a real-world case study in a mountainous area where the natural terrain gradient is nearly triple the maximum allowed design gradient. The results show that this methodology can automatically find various promising alternatives, while satisfying the complex constraints.

Keywords: Railway design; Railway alignment; Alignment optimization; Distance transform
\end{abstract}

\section{Introduction}

Railway alignment design is quite complex and time-consuming because various factors should be considered and multiple design constraints must be satisfied. In theory, the designer should find a near-optimal solution among infinite numbers of alternatives connecting given railway start and end points. However, designers can only afford the analysis of a few routes since the time and resources are limited. Thus, many potential promising alternatives may be overlooked.

To overcome such limitations and improve search efficiency and solution quality, numerous researchers have devoted great efforts to railway and highway alignment optimization. They have mostly tried to formulate railway alignment design as an optimization problem. Many methods have been developed for optimizing highway or railway alignment. It is known that the alignment is determined by the distribution of points of intersection (PIs) and curve configurations. Therefore, the optimization problem is basically to determine the locations of a set of PIs and their curve configurations. According to differences in their calculation process, the optimization approaches can be classed into direct and indirect approaches, as shown in Table 1. Some approaches formulate the optimization model by treating the PIs' coordinates and radii as variables and determine them directly. The others generate the optimal path first, and then derive from it the final PI locations and radii. Although the direct methods can determine the PIs' coordinates and radii directly, they need to preset the initial distribution of PIs, which crucially affects the results.

\footnotetext{
* Corresponding author. Tel.: +86 139731196 32; fax: +86 73185571736 .

E-mail addresses: leewei@csu.edu.cn (W. Li), haopu@csu.edu.cn (H. Pu), pschon@umd.edu (P. Schonfeld), zhanghongfblw@csu.edu.cn (H. Zhang), zhengxq@csu.edu.cn (X. Zheng). 
Table 1 Approaches for railway or highway alignment optimization

\begin{tabular}{|l|l|l|}
\hline Class & Optimization approach & References \\
\hline \multirow{5}{*}{ Direct } & Calculus of variations & $\begin{array}{l}\text { Howard et al. (1968), Shaw and Howard (1981, 1982), Thomson } \\
\text { and Sykes (1988), and Wan (1995) }\end{array}$ \\
\cline { 2 - 3 } & Enumeration & Easa (1988) \\
\cline { 2 - 3 } & Linear programming & ReVelle et al. (1997), Chapra and Canale (2006) \\
\cline { 2 - 3 } & Numerical search & Hayman (1970), Robinson (1973) and Chew et al. (1989) \\
\cline { 2 - 3 } & Genetic algorithms & $\begin{array}{l}\text { Jong (1998), Jong and Schonfeld (2003), Jha and Schonfeld } \\
\text { (2004), Kim et al. (2005, 2007), Kang et al. (2009, 2010, 2012) }\end{array}$ \\
\cline { 2 - 3 } & Particle swarm optimization & Shafahi and Bagherian (2013) \\
\hline \multirow{5}{*}{ Indirect } & Network optimization & $\begin{array}{l}\text { Turner and Miles (1971), OECD (1973), Athanassoulis and } \\
\text { Calogero (1973), Parker (1977),and Trietsch (1987a,b) }\end{array}$ \\
\cline { 2 - 3 } & Dynamic programming & $\begin{array}{l}\text { Hogan (1973), Nicholson et al. (1976), Puy Huarte (1973), } \\
\text { Murchland (1973), Goh et al. (1988), Fwa (1989), Li et al.(2013) }\end{array}$ \\
\cline { 2 - 3 } & Mixed integer programming & Easa and Mehmood (2008) \\
\cline { 2 - 3 } & $\begin{array}{l}\text { Neighborhood } \\
\text { heuristic with mixed integer } \\
\text { programming }\end{array}$ & Cheng and Lee (2006), Lee et al. (2009) \\
\cline { 2 - 3 } & Distance transform & Mandow and Perez-de-la-Cruz (2004) and De Smith (2006) \\
\cline { 2 - 3 } & Discrete algorithms & Mondal et al. (2015), Hirpa et al. (2016), Pushak et al. (2016) \\
\hline
\end{tabular}

Among direct methods, genetic algorithms (GAs) have been the most popularly adopted methods for optimizing railway or highway alignments in the past decade (Shafahi and Bagherian, 2013). They have been developed by a University of Maryland research group. Jong and Schonfeld (1998) developed the original highway alignment optimizing (HAO) methodology based on GAs. They preset series of cutting planes perpendicular to the straight line linking the start and end points. The alignment PIs are generated on these planes. The coordinates of the PIs are defined as the genes and eight mutation and crossover operators are proposed to search for alternatives.

Further HAO improvements were provided in later studies. Backtracking alignments were developed for unusually difficult terrain and land use (Jong and Schonfeld, 2003). To solve real-world problems while considering complex land and environmental features, the HAO was combined with detailed geographic information system (GIS) databases (Jha and Schonfeld, 2004). A stepwise genetic algorithms approach (Kim et al., 2005) and a prescreening and repairing method for handling infeasible solutions (Kang, Schonfeld and Yang, 2009) were proposed to improve computational efficiency. Since railway design criteria, constraints and objective function are different from those for highways, Jha, Schonfeld and Samanta (2007) developed a model for optimizing rail transit routes with GAs and GIS. This was extended by Lai and Schonfeld (2010, 2012, 2016) to optimize rail transit line alignments concurrently with the locations of stations along those lines. In the above models, the candidates are evaluated with one single-objective function, but multi-objective highway alignment optimization models have also been proposed (Samanta and Jha, 2011, Yang et al., 2014). Shafahi and Bagherian (2013) proposed a customized particle swarm optimization (PSO) algorithm, inspired by the social behavior of bird flocking and fish schooling, to search for a near-optimal highway alignment. This is a viable alternative to GAs.

The direct methods need to determine the number and initial distribution of PIs, which normally are accomplished by presetting cutting planes perpendicularly to the straight line linking the start and end points. Therefore, these methods can be also named cutting planes model approaches. They are efficient in optimizing alignments in areas without great topographic complexity, where the natural terrain gradient $\left(i_{T}\right)$ is smaller than the maximum allowed design gradient $\left(i_{D}\right)$. However, if $i_{T}$ greatly exceeds $i_{D}$, this method may fail to generate feasible alternatives. This is partly due to the routes having to be circuitous to guarantee enough length for overcoming the huge elevation difference. Obviously then, the cutting planes cannot be distributed along the shortest connecting line. The reasonable alignments must satisfy various complex constraints, which include acceptable gradients despite huge elevation differences between the alignment start and end point, bridge heights and tunnel lengths limited by current construction technology, and many obstacles to overcome. An unsuitable distribution of cutting planes may result in failing to generate acceptable alignments. Determining in which direction and at what intervals to preset the cutting planes are very difficult tasks. Since indirect methods 
need not preset cutting planes, they seem more suitable for optimizing alignments in complex mountainous area where $i_{T}$ greatly exceeds $i_{D}$.

Recently, researchers at the Centre for Optimization, Convex Analysis \& Nonsmooth Analysis in University of British Columbia, Okanagan Campus have developed some remarkable methods for road alignment optimization. They developed a novel bi-objective optimization framework for three-dimensional road alignments, in which earthwork cost and utility costs are cast (Hirpa et al., 2016). Their comparative numerical results from five algorithms used to solve a dissimilar multipath problem show that a bidirectional approach yields the fastest running times and the most robust algorithm (Pushak et al., 2016). The NOMAD (Nonlinear Optimization with Mesh Adaptive Direct Search) and the HOPSPACK (Hybrid Optimization Parallel Search Package) were used by researchers from the same team for optimizing horizontal alignment in a specified corridor (Mondal et al., 2015). These methods which first generate multiple corridors and then refine them into alignments further extend indirect methods.

Essentially, railway alignment design is a shortest path problem, in which the distance between random two points can be represented by the comprehensive cost, including construction, operating and maintenance and other costs. Among the shortest path finding algorithms, the distance transform (Rosenfeld, 1966) is an efficient method, which can quickly find the minimum Euclidean distances from every cell of a rectangular lattice to the target cell. It was originally designed for image processing and then widely applied to many fields, including finding shortest paths (Shih and $\mathrm{Wu}, 2004$ ), skeleton extraction (Beristain and Grana, 2010) and image segmentation (Liu and Zhao, 2010). In the transportation field, De Smith (2006) developed a gradient-constrained distance transform (DT) and applied it to railway and road alignment design. This model can generate optimal 3d paths satisfying the gradient constraint. However, multiple other constraints must also be satisfied for railway alignments in complex mountainous areas. If all the constraints are considered in this algorithm, it can hardly generate feasible path. Hence, this algorithm needs further improvement before it can be applied to railway alignments in mountainous areas.

We propose to solve the mountainous alignment optimization problem through two steps:

(i) Generate promising 3D railway paths satisfying multiple constraints using an improved distance transform.

(ii) Select representative paths and fit them to generate the optimal alignment and various promising alternatives.

This method can not only overcome the weaknesses of previous cutting planes model approaches, but also improve the previous DT to satisfy the complex constraints in mountainous areas.

\section{Comprehensive geographic information}

It is desirable that a model for optimizing railway alignment should exploit a GIS database because massive amounts of spatial data such as topography, soil conditions, forbidden areas, unit costs of earthwork, bridges, tunnels and right of way, are essential for railway alignment design. We develop a comprehensive geographic information model (CGIM) to store and manage these data. Topography is often represented using a regular rectangular lattice of points or cells for which elevation values are provided. The data sets of this form are known as digital elevation model (DEM) data. Similarly to the DEM, the data structure of CGIM is also a regular rectangular lattice and has the same dimensions. All the needed geographic information is stored in the cells. Fig.1 shows the CGIM structure. Based on the CGIM, we optimize 3D paths in the lattice using the DT.

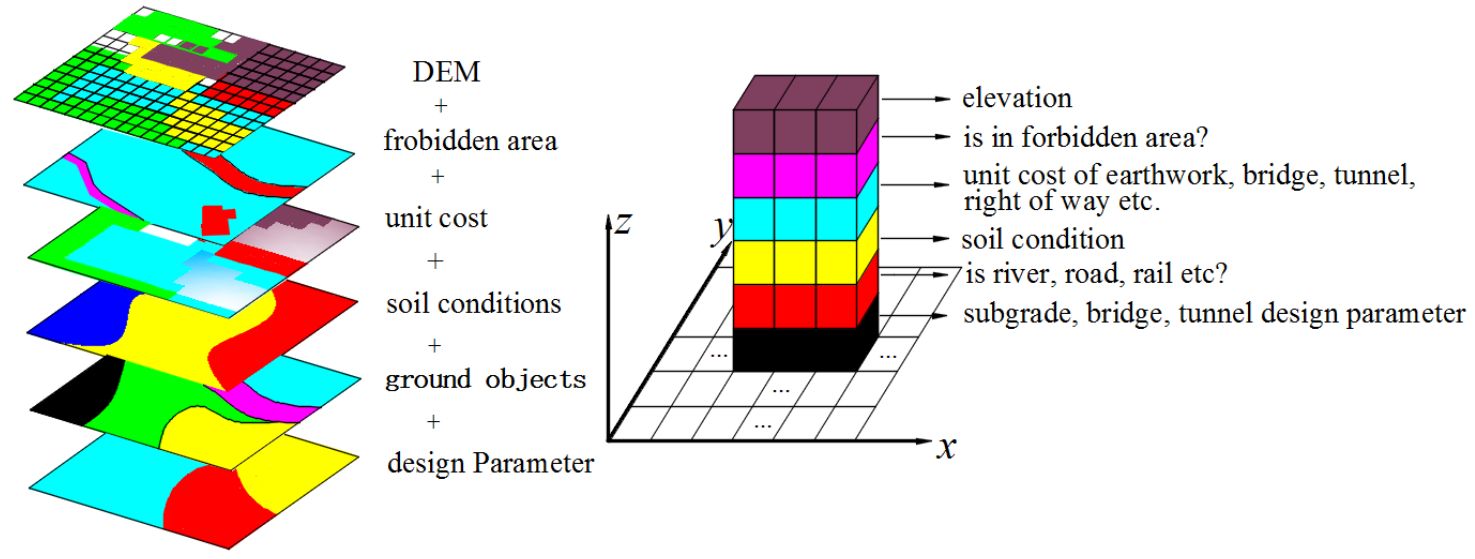

Fig. 1. Comprehensive geographic information model 


\section{Distance transform}

Distance transform (DT) algorithms (De Smith, 2006) provide a very simple and extremely fast method for the approximation Euclidean distances from every cell of a rectangular lattice to the nearest cell in a target set. The global distances are approximated by prorogating local distances i.e., distances between neighboring cells. The neighboring cells are called neighboring mask which is described as an adjacency matrix $\boldsymbol{M}_{\boldsymbol{d}}$. A $5 \times 5$ adjacency matrix is shown in Fig. 2. The element $d_{r, c}$ in the matrix $\boldsymbol{M}_{\boldsymbol{d}}$ is the Euclidean distance from the cell (at row $r$, column $c$ in the neighboring mask) to the center cell. The whole matrix can be divided into two parts: the upper left part and the lower right part, which are, respectively, employed by the forward and backward scan.

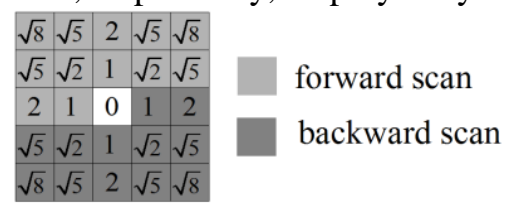

Fig. 2. Neighboring mask

Firstly, the distance of each cell in the lattice is initialized. The value of the target cell is zero, and the others are infinity. Then, a two-pass scan of the lattice data is conducted: a forward scan from the top left to the bottom right, and then a backward scan from the bottom right to the top left. When one cell is scanned, the center of the neighboring mask is placed over it, and the local distance $d_{r, c}$ is added to the value of the cell. The new value of this cell is the minimum of all the sums. This process is repeated until no cell value changes. The final value of every cell in the lattice is the minimum distance to the target.

In this process, we assume $p$ is one random cell in the lattice, while $D(p), \Delta R(p)$, and $\Delta C(p)$ are stored in this cell.

$D(p)$ is the minimum distance from $p$ to the target cell.

$\Delta R(p)$ and $\Delta C(p)$ are the incremental row and column movements at $p$ in the corresponding shortest path.

The standard algorithm first initializes the $D, \Delta R, \Delta C$ value for all cells:

$$
\begin{aligned}
& D^{0}(p)= \begin{cases}0 & p \in B, \\
\infty & p \notin B,\end{cases} \\
& \Delta R(p)=0, \\
& \Delta C(p)=0,
\end{aligned}
$$

where $B$ is the target set and the superscript of $D$ is the iteration.

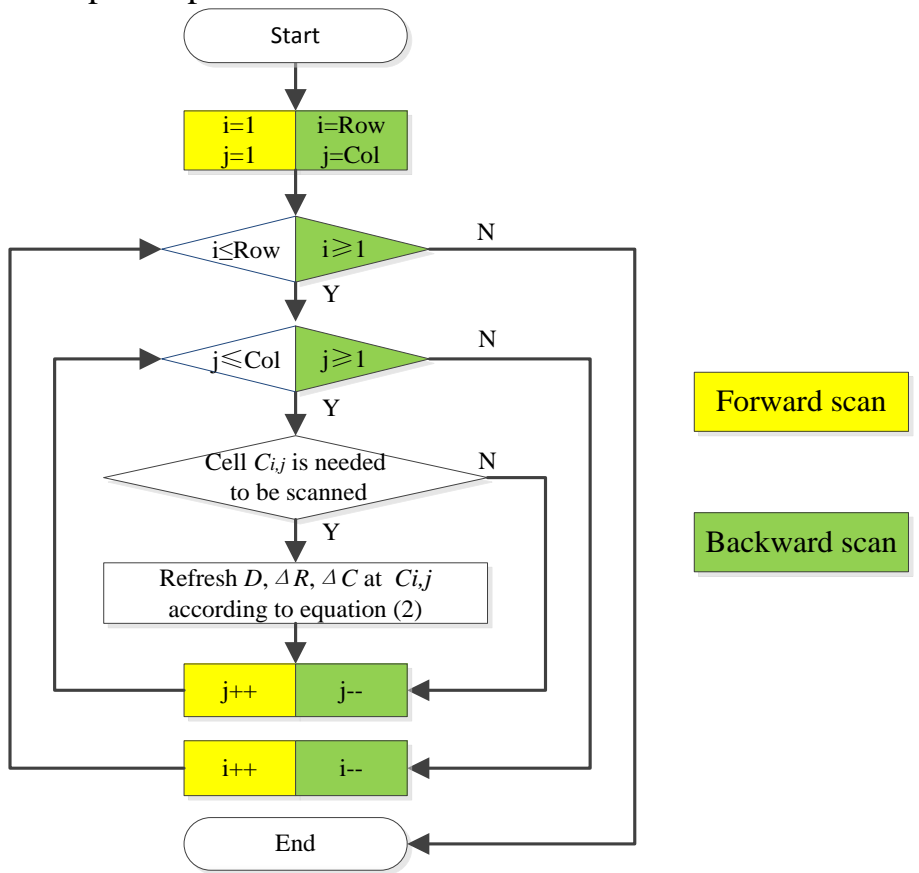

Fig. 3. Two-pass scan in DT

Then, a two-pass scan of the lattice data is conducted: a forward scan from the top left to the bottom right, and 
then a backward scan from the bottom right to the top left (Fig.3). When cell $p$ is scanned, its values are refreshed by following equation:

$$
\begin{aligned}
& D^{t}(p)=\min _{r, c}\left\{D^{t-1}(q)+d_{r, c}\right\}, \\
& \Delta R(p)=r, \\
& \Delta C(p)=c,
\end{aligned}
$$

where $D^{t}(p)$ is the new value at $p$ (i.e. the central cell in the neighboring mask), $q$ is one random cell in the neighboring mask, $D^{t-1}(q)$ is the current distance value at $q$ and $d_{r, c}$ is the local distance from $p$ to $q$. Fig. 4 is a simple case, in which $r=-1, c=-1$, the value of $D^{t-1}(q)+d_{r, c}$ get the minimum value so the new $D^{t}(p)=D^{t-1}(q)+$ $d_{-1,-1}, \Delta R(p)=-1, \Delta C(p)=-1$.
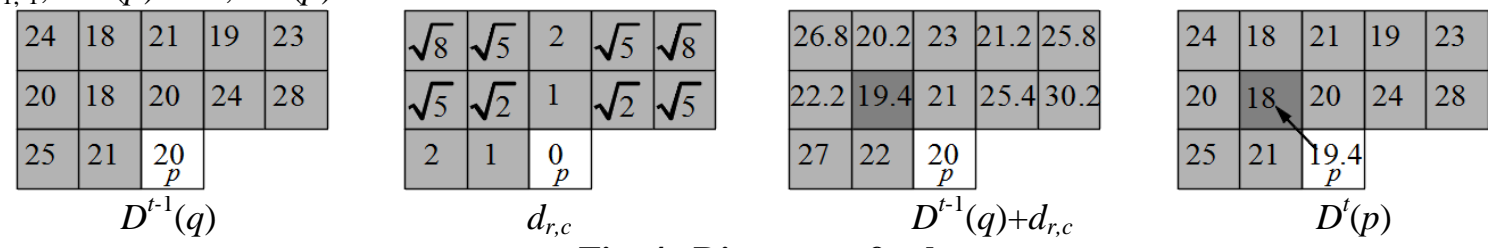

Fig. 4. Distance refresh process

The above two-pass scan is carried out until the value of $D$ at every cell is static. The final $D(p)$ is the minimum distance from $p$ to the nearest target. As shown in Fig. 5, the corresponding shortest path can be generated by the $\Delta R(p)$ and $\Delta C(p)$.

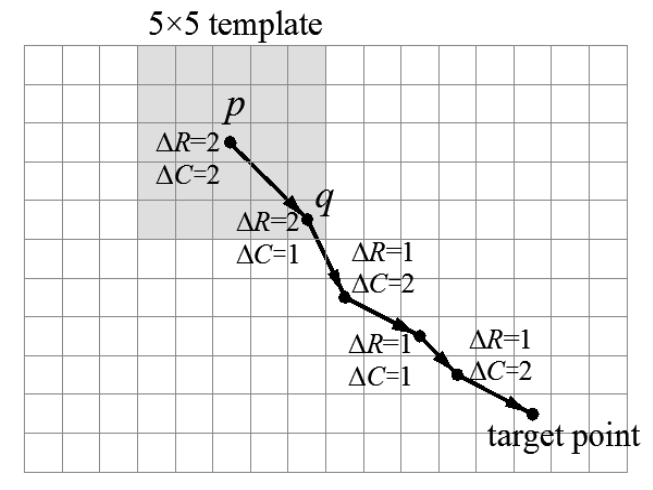

Neighbooring template

Fig. 5. Generation of the shortest path from $p$ to the target point

On completion of the two-pass scan, each cell in the resulting lattice will contain the minimum distance to the target point. We represent the distance using the path cost and set the alignment endpoint as the target point. Then, the cell distance value in the resulting lattice is the minimum cost to the endpoint and the corresponding path is the optimizing path. In railway alignment optimization, the distance should be replaced by the link cost.

\section{Improved distance transform}

\subsection{Link cost}

$C_{i, j}$ is a random cell in the lattice located at row $i$, column $j$, whose $3 \mathrm{D}$ coordinates are $\left(X_{i, j}, Y_{i, j}, H_{i, j}\right) . C_{r, c}$ is another cell in the lattice, located at row $r$, column $c$, whose 3D coordinates are $\left(X_{r, c}, Y_{r, c}, H_{r, c}\right)$. If these two cells are linked, a local alignment can be generated. The horizontal and vertical alignments are shown in Fig. 6.

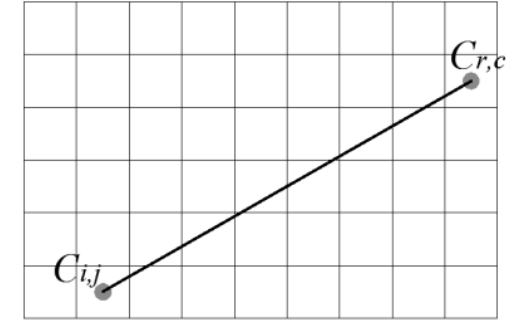

a. Horizontal alignment

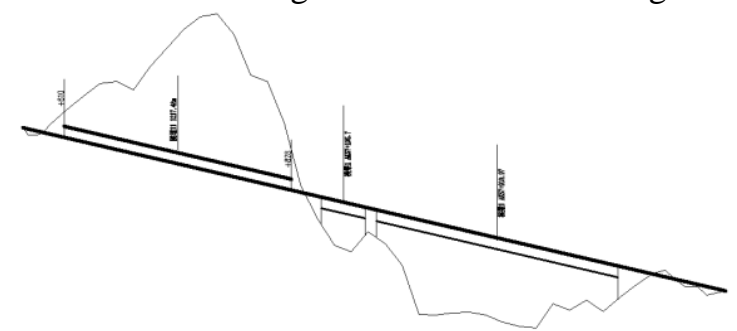

b. Vertical alignment

Fig. 6. Local alignment linked by two cells 
The link cost between $C_{i, j}$ and $C_{r, c}$ is defined as the local alignment cost. Before calculating the alignment cost, the locations of railway construction elements including bridges, tunnels, and subgrades should be set. The main procedure is as follows:

(1) Convert the alignment to a set of points (known as stations).

(2) Interpolate the ground elevation of the stations based on DEM.

(3) Compute the fill or cut height $(\Delta \mathrm{h})$ for all stations.

(4) Auto-set the locations of bridges, tunnels and subgrades according to the stations' $\Delta \mathrm{h}$. ( Li, 2014)

The cost is composed of four parts: (1) Construction costs, including bridges, tunnels, earthwork and length-dependent costs; (2) right-of-way costs, which are obtained from the intersection of the alignment with the right of way lattice in the CGIM; (3) operating costs sensitive to the alignment; and (4) environmental impact costs.

\subsubsection{Construction costs}

(1) The cost of bridges $C_{B}$ is:

$$
C_{B}=\sum_{i=1}^{n}\left(U_{B i} \times L_{i}+2 C_{A i}\right),
$$

where $n=$ number of bridges (integer),

$L_{i}=$ length of the $i^{\text {th }}$ bridge (m),

$C_{A i}=$ one abutment cost of the $i^{\text {th }}$ bridge ( $\left.¥\right)$,

$U_{B i}=$ unit length cost of the $i^{\text {th }}$ bridge $(¥ / \mathrm{m})$.

(2) The cost of tunnels $C_{T}$ is:

$$
C_{T}=\sum_{i=1}^{n} U_{T i} \times L_{i}+2 \times C_{P i},
$$

where $n=$ number of tunnels (integer),

$L_{i}=$ length of the $i^{\text {th }}$ tunnel (m),

$C_{P i}=$ one tunnel portal cost of the $i^{\text {th }}$ tunnel (¥),

$U_{T i}=$ unit length cost of the $i^{\text {th }}$ tunnel ( $\left.¥ / \mathrm{m}\right)$.

(3) For earthwork costs $C_{E}$ we use the "Average End Area" method (Wright, 1996) to calculate cut and fill volumes. First, the cross section area $S$ is calculated:

$$
S=2\left(W_{S}+\Delta h \times i\right) \times \Delta h
$$

where $W_{S}=$ width of the subgrade surface $(\mathrm{m})$,

$\Delta h=$ fill or cut height $(\mathrm{m})$,

$i=$ fill or cut slope ratio (real).

The earthwork costs are:

$$
C_{E}=\sum_{i=1}^{m-1} U_{F i} \times\left(L_{i+1}-L_{i}\right) \times\left(S_{i}+S_{i+1}\right) / 2+\sum_{i=1}^{n-1} U_{C i} \times\left(L_{i+1}-L_{i}\right) \times\left(S_{i}+S_{i+1}\right) / 2,
$$

where $U_{C i}, U_{F i}=$ unit cut $/$ fill cost of the $i^{\text {th }}$ cross section $\left(¥ / \mathrm{m}^{3}\right)$,

$m, n=$ number of cut/fill cross sections (integer),

$S_{i}=$ area of the $i^{\text {th }}$ cross section $\left(\mathrm{m}^{2}\right)$,

$L_{i}=$ mileage of the $i^{\text {th }}$ cross section (m).

(4) Other length-dependent construction costs, which are the cost of each unit length of an alignment, can be calculated directly by multiplying the unit cost per length in each possible solution. They include the rail track, and traction equipment:

$$
C_{L}=U_{L} \times L,
$$

where $U_{L}=$ total unit length-dependent construction cost $(¥ / \mathrm{m})$,

$L=$ total alignment length (m).

\subsubsection{Right of way costs}

Right of way costs are calculated by the intersection of the alignment with the right of way cells in the CGIM: 


$$
C_{R}=\sum_{i=1}^{n-1} U_{i} \times\left(L_{i+1}-L_{i}\right) \times\left(W_{i}+W_{i+1}\right) / 2,
$$

where $U_{i}=$ unit right of way cost of the $i^{\text {th }}$ station $\left(¥ / \mathrm{m}^{2}\right)$,

$n=$ number of stations (integer),

$W_{i}=$ right of way width of the $i^{\text {th }}$ station (m).

\subsubsection{Operating costs}

According to the China Railway Engineering Design Manual-Alignment (CREDMA, 1999), three parts of operating costs are sensitive to the alignment: operating costs related to gradient, intersection angle and length.

(1) The perating cost sensitive to gradient is:

$$
C_{G}=365 \times N \times \sum_{i=1}^{n} e_{i} \times l_{i},
$$

where $N=$ number of daily vehicles in double directions (vehicles/day),

$n=$ number of gradient sections (integer),

$l_{i}=$ length of $i^{\text {th }}$ gradient sections (m). 1999).

$e_{i}=$ statistical factor related to the gradient and locomotive ( $¥ / \mathrm{km} \cdot$ vehicle). It can be found in (CREDMA,

(2) The operating cost sensitive to intersection angle is:

$$
C_{A}=0.0122 \times 365 \times N \times A \times(P+Q) \times a \times 10^{-3},
$$

where $N=$ number of daily vehicles in double directions (vehicles/day),

$A=$ alignment total intersection angles (degree),

$\alpha=$ statistical factor related to the locomotive $(¥ / \mathrm{km} \cdot \mathrm{t})$, which can be found in CREDMA,

$P=$ locomotive quality $(\mathrm{t})$,

$Q=$ tractive tonnage $(\mathrm{t})$.

(3) The operating cost sensitive to length is:

$$
C_{M}=U_{M} \times L,
$$

where $U_{M}=$ statistical factor $(¥ / \mathrm{km})$ related to the tractive tonnage, track standard, signal block mode. It is listed in (CREDMA, 1999),

$$
L=\text { length of the alignment }(\mathrm{km}) \text {. }
$$

\subsubsection{Environmental impact costs}

If the alignment passes through environment sensitive regions, a penalty $C_{I}$ is added to the total costs:

$$
C_{I}=\sum_{i=1}^{n} U_{i} \times S_{i}
$$

where $U_{i}=$ unit penalty cost of the $i^{\text {th }}$ environmentally sensitive region $\left(¥ / \mathrm{m}^{2}\right)$,

$S_{i}=$ area of the railway intersecting with the $i^{\text {th }}$ environmentally sensitive region $\left(\mathrm{m}^{2}\right)$.

Among above costs, $C_{B}+C_{T}+C_{E}+C_{R}+C_{L}+C_{I}$ are the total construction costs. $C_{A}+C_{G}+C_{M}$ are the annual costs. For consistency of units in this function, the total construction costs are converted to annual construction costs by multiplying them with the capital recovery factor $\Delta$ :

$$
\Delta=\frac{i(1+i)^{n}}{(1+i)^{n}-1},
$$

where $i=$ interest rate (\% per period),

$n=$ number of compounding periods (economic life). It is usually set as 30 years in China.

The sum of annual construction costs and annual operating costs is the annual comprehensive cost:

$$
C=\Delta\left(C_{B}+C_{T}+C_{E}+C_{R}+C_{L}+C_{I}\right)+C_{A}+C_{G}+C_{M} .
$$

\subsection{Preprocess lattice}

In the traditional distance transform, every cell must be scanned and the best link cell must be found in its neighboring mask. That is time-consuming work. To reduce the calculation burden, we check all the cells in the lattice before applying the DT. If the cell is unreachable or located in a forbidden area, it will be skipped in the 
scanning. It is easy to judge whether one cell is in a forbidden area, because the relevant property is stored in the CGIM. Whether a cell is reachable can be calculated.

Assume the alignment start and end cells are respectively $S\left(i_{S}, j_{S}\right), \quad E\left(i_{E}, j_{E}\right)$, elevations are $H_{\mathrm{S}}$ and $H_{\mathrm{E}} . l_{\mathrm{S}}$ and $l_{\mathrm{E}}$ are the air-line distances from the cell $C_{i, j}$ to the start point and end point. The maximum allowable circuity coefficient is $\gamma_{\max }$. The cell width in the lattice is $w$. $C_{i, j}$ must satisfy following condition; otherwise it is unreachable:

$$
\begin{aligned}
& l_{S}=\sqrt{\left(i-i_{S}\right)^{2}+\left(j-j_{S}\right)^{2}} \times w, \\
& l_{E}=\sqrt{\left(i-i_{E}\right)^{2}+\left(j-j_{E}\right)^{2}} \times w, \\
& \left(l_{S}+l_{E}\right) / l_{S E}<\gamma_{\max } .
\end{aligned}
$$

Considering the vertical attainability, the alignment must be long enough to overcome the elevation difference between the start and end points. This condition is:

$$
\left(l_{S}+l_{E}\right) \times \gamma_{\max } \times i_{\max }>\left|H_{E}-H_{S}\right|,
$$

where, $i_{\max }$ is maximum allowed design gradient.

Besides, the reasonable railway elevation value range at $C_{i, j}$ must not be empty:

$$
\begin{aligned}
& H_{\mathrm{S}, \text { max }}=H_{\mathrm{S}}+i_{\text {max }} \times l_{\mathrm{S}} \times \gamma_{\text {max }}, H_{S, \text { min }}=H_{\mathrm{S}}-i_{\text {max }} \times l_{\mathrm{S}} \times \gamma_{\text {max }}, \\
& H_{\mathrm{E}, \text { max }}=H_{\mathrm{E}}+i_{\text {max }} \times l_{\mathrm{E}} \times \gamma_{\text {max }}, H_{\mathrm{E}, \text { min }}=H_{\mathrm{S}}-i_{\text {max }} \times l_{\mathrm{E}} \times \gamma_{\text {max }}, \\
& U=\left[H_{S, \text { min }}, H_{\mathrm{S}, \text { max }}\right] \cap\left[H_{E, \text { min }}, H_{E, \text { max }}\right] .
\end{aligned}
$$

If $U \neq \varnothing$, this cell is vertically reachable; otherwise it is unreachable.

Benefitting from the above preprocess, some unreachable cells can be skipped and the computation time can be significantly reduced.

\subsection{Handling alignment constraints}

There are multiple constraints affecting the alignment design, such as maximum gradient, minimum radius, forbidden zones, maximum pier height, and maximum tunnel length. These constraints can be divided into three types: geometric constraints, structure constraints and location constraints.

\subsubsection{Geometric constraints}

The alignment must meet design criteria. In this study, according to China's code for design of railway lines, the minimum radius and length of the horizontal circular curves, the minimum length of tangent between two adjacent horizontal curves, and the maximum gradient of each section in vertical alignments must be satisfied. In the path searching phase, we handle the maximum gradient. The others will be considered in the alignment fitting phase.

If the gradient between $C_{i, j}$ and $C_{r, c}$ exceeds the maximum allowable gradient, this link must be forbidden. This can be expressed as:

$$
\frac{\left|H_{r, c}-H_{i, j}\right|}{w \sqrt{(i-r)^{2}+(j-c)^{2}}} \leq i_{\max } .
$$

\subsubsection{Structure constraints}

In mountainous terrain, numerous bridges and tunnels are probably needed. As limited by current construction techniques, a bridge cannot be built if any of its piers exceeds the maximum allowable pier height; a tunnel is also infeasible if it exceeds the maximum allowable tunnel length. Subgrades located on steep ground are dangerous and should be avoided in the route design. Moreover, the locations of bridges, tunnels and subgrades are confined by the geological conditions. Since the needed information has been stored in CGIM, it is easy to check whether a path satisfies all these constraints.

\subsubsection{Location constraints}

\section{(1) Forbidden zone}

To protect the environment or bypass high cost areas, various forbidden zones (nature protection areas, commercial centers, residential areas, etc.) are specified. The 3D paths must not pass through these zones. Using 
CGIM, we check the cells which are traversed by the local alignment; if one of them is in forbidden areas, this link is forbidden.

\section{(2) Crossing constraints}

The alignment may have to cross existing rivers, roads and railways in the study area. When the 3D path passes through these cells, we should check the difference between the vertical design elevation and the cell elevation to guarantee sufficient clearance before allowing this link.

\section{(3) Elevation tendency}

To overcome a huge elevation difference the designer successively increases or reduces the route vertical elevation until the target elevation is reached. We call this elevation tendency. It appears frequently in complex mountains. Thus, if the target elevation is far above the current point, the higher cells in the neighboring mask should be linked preferentially.

When a connection between cells $C_{i, j}$ and $C_{r, c}$ is considered, all above constraints should be checked. If any constraint cannot be satisfied this link will be rejected.

\subsection{Adaptive neighboring mask}

There may be no linkable cells in the neighboring mask for some cells during the scan, since multiple constraints apply. These cells are invalid. The path cannot be formed from an invalid cell to the target point. If many such cells exist, there will be no path linking the railway start and end points. To overcome this problem, an adaptive neighboring mask is defined. If there is no linkable cell in the preset standard neighboring mask, the neighboring mask will be extended adaptively.

As shown in Fig. 7, this neighboring mask includes two parts: inner standard $n_{N} \times n_{N}$ neighboring mask and outer extended $n_{W} \times n_{W}$ neighboring mask. $n_{N}$ is a static value which can be determined with De Smith's (2006) method. However, $n_{W}$ is an adaptive value depending on the topography and constraints.

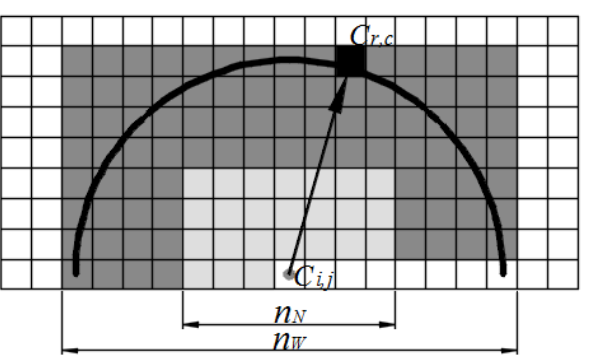

a. Forward mask
First linkable cell

Standard neighboring mask

Extended neighboring mask

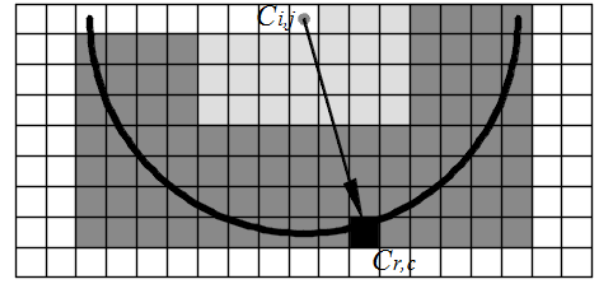

b. Backward mask

Fig. 7. Dynamic adaptive neighboring mask

When cell $C_{i, j}$ is scanned, if there are linkable cells in the standard neighboring mask, the extended neighboring mask is not needed. Otherwise, as shown in Fig. 7, we traverse the cells from inside out until one linkable cell $C_{r, c}$ is found, which satisfies all the constraints. The extended neighboring mask size $n_{W}$ is determined by following relations:

$$
\begin{aligned}
& n_{W}=2 \times \max (|r-i|,|c-j|)+1, \\
& n_{W}<2 \times L_{\max } / w+1,
\end{aligned}
$$

where $L_{\max }$ is the admissible maximum distance between two linked cells. We usually set it to be the admissible maximum bridge or tunnel length.

\subsection{Bidirectional scanning strategy}

Setting the railway end point cell as the target, the optimal path from one random cell $C_{i, j}$ to the end point can be generated by a multi-constrained distance transform. If $C_{i, j}$ is the railway start point, this path is the optimal path we are seeking. However, at most one path can be found. Multiple constraints in mountains may even result in no feasible path. Moreover, the designers usually need various possible paths to avoid overlooking valuable candidates. Therefore, we use the bidirectional scanning strategy to generate various paths.

Firstly, the end point cell is set as the target to generate the end distance image $\mathrm{DT}_{\mathrm{E}}$ Similarly, the start distance image $\mathrm{DT}_{\mathrm{S}}$ is formed by setting the start point cell as the target. Then, we traverse all the cells in the lattice to generate various $3 \mathrm{D}$ paths. The paths from $C_{i, j}$ to the start and end points can be found, respectively, by 
$\mathrm{DT}_{\mathrm{S}}$ and $\mathrm{DT}_{\mathrm{E}}$. Linking the above two paths, the integrated path via $C_{i, j}$ is generated (Fig. 8).

Using the above strategy, a set of 3D paths can be generated. Then, the paths are sorted by their comprehensive costs. At the next stage, they will be fitted to the final alignments.

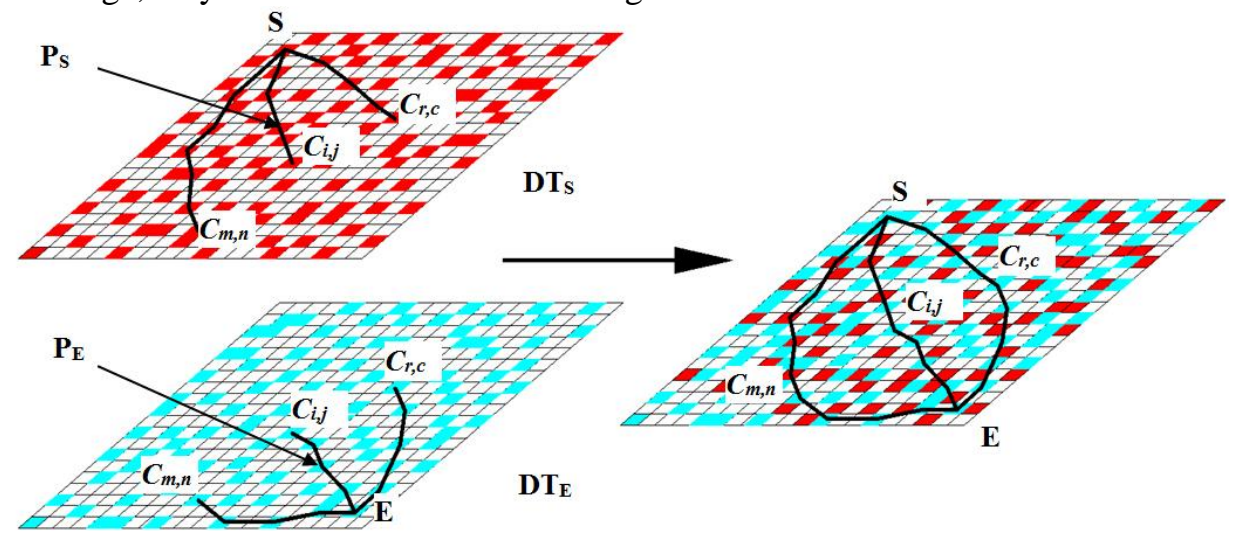

Fig. 8. Generating paths with bidirectional scanning

\section{Fitting paths to alignments}

Benefitting from the above distance transform, a set of $3 \mathrm{~d}$ paths satisfying various constraints is generated. Not only the geometrical coordinates but also the bridges, tunnels and subgrades locations which are formed in the link cost calculations are stored in every path. However, the $3 \mathrm{~d}$ polyline path is not a smooth curve conforming to the railway alignment design requirements. The path should be refined into the final alignment. The path fitting process includes initializing and optimizing the alignment.

\subsection{Initial alignment}

The horizontal alignment can be determined by the PIs coordinates and corresponding circular curve radii. We use the dichotomy to select feature points in the polyline path as the PIs to generate the initial alignment with the minimum circular curve radii. We first form the initial edge linking the path start and end points; then find the feature point with the maximum distance to the edge and split this edge into 2 parts at the feature point; finally, we incrementally split edges until all the distances to edges are below the allowed minimum distance $d_{\min }$. Assume the points along a path include $P_{0} \ldots P_{n}$. The alignment is initialized by incrementally inserting PIs. All the PIs of the initial alignment are stored in a set $U_{P I}$. The process is as follows:

Step (1) Set the allowed minimum distance $d_{\text {min }}$; insert $P_{0}$ and $P_{n}$ to the $U_{\mathrm{PI}}$; Link $P_{0}$ to $P_{n}$ and form the initial edge $L_{\mathrm{S}, \mathrm{E}}(S=0, E=n)$.

Step (2) As shown in Fig. 9a, calculate the distances $D_{i}$ from $P_{S+1} \ldots P_{E-1}$ to $L_{S, E}$; if the maximum distance $D_{M}<d_{\min }$, no PI can be inserted and the process goes to step (5), otherwise it goes to step (3)

Step (3) Insert $P_{M}$ into $U_{P I}$ and split $L_{S, E}$ into two edges: $L_{S, M}$ and $L_{M, E}$ (Fig.9 b).

Step (4) Incrementally conduct step (2) and step (3) on $L_{S, M}$ and $L_{M, E}$, until none of the edges can be split.

Step (5) Generate the initial alignment using the PIs in $U_{\mathrm{PI}}$ with the minimum radii (Fig. 9c).

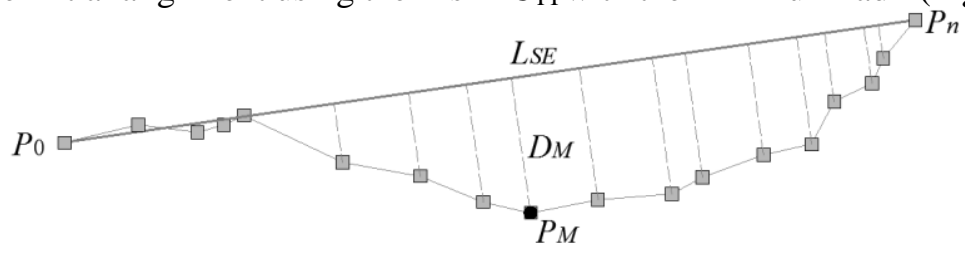

a. Find PI

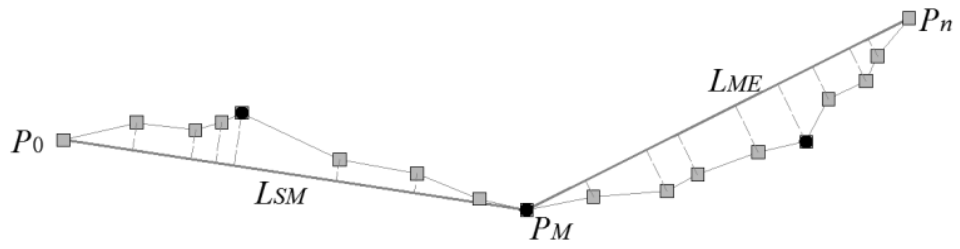

b. Insert PI and split edge 


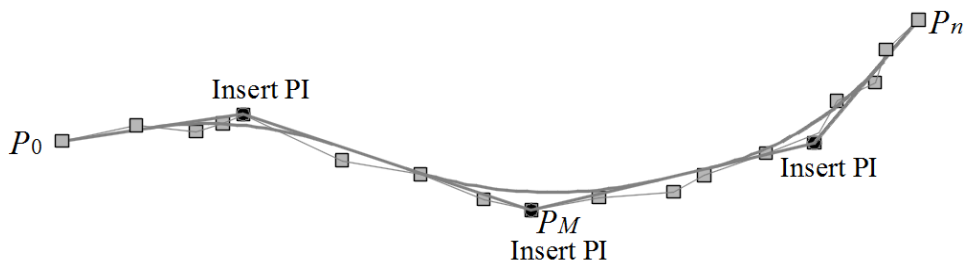

c. Initial alignment

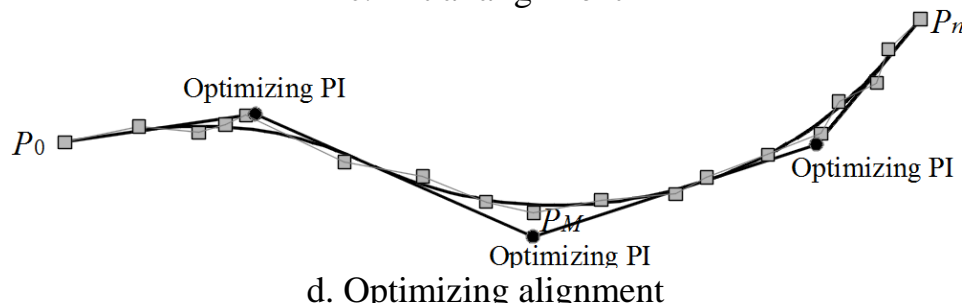

Fig. 9. Refining path into alignment

\subsection{Optimize alignment}

To obtain the best alignment we optimize the initial alignment. The optimization model can be described as:

$$
\begin{aligned}
& \min f(\boldsymbol{p})=\sum_{i=1}^{m} d_{i}^{2}(\boldsymbol{p}), \\
& \boldsymbol{p}=\left[X_{1}, X_{2}, \ldots, X_{n}, Y_{1}, Y_{2}, \ldots, Y_{n}, R_{1}, R_{2}, \ldots, R_{n}\right]^{\mathrm{T}},
\end{aligned}
$$

where $m=$ number of the points in the polyline path,

$d_{i}=$ distance from the $i^{\text {th }}$ point in the polyline path to the alignment generated by $\boldsymbol{p}$,

$n=$ number of PIs in the alignment,

$X_{i}, Y_{i}=$ the horizontal coordinates of the $i^{\text {th }} \mathrm{PI}$,

$R_{i}=$ corresponding curve radius of the $i^{\text {th }} \mathrm{PI}$.

It is difficult to describe the objective function with an analytic expression since the alignment consists of many straight and circular curve elements. The mesh adaptive direct search (MADS) algorithm (Audet and Dennis, 2006) is a pattern search method which does not need an explicit objective function. Based on the MADS algorithm, the NOMAD optimization software (Audet et al., 2009, Abramson et al., 2016) has been developed and is freely available. It can efficiently explore a design space in search of better solutions for a wide spectrum of optimization problems. NOMAD has been adopted for solving this optimization problem after performance comparisons with other optimization methods (Monda et al., 2015). We have embedded the objective function evaluation in $\mathrm{C}++$ source code to be linked with the NOMAD library. Thus, NOMAD has been used to optimize the parameters representing the horizontal alignment (Fig. 9d).

Using the mileages and heights of vertical points of intersection as the design variables, the vertical alignment can also be optimized through NOMAD.

\section{A real-world case study}

This approach has been employed by the China Railway Eryuan Engineering Group CO. LTD and has been applied to the Sichuan-Tibet, Tongdao-Quanzhou and Zhengzhou-Guiyang railway alignment designs. We use one section of the Sichuan-Tibet railway as a case study.

\subsection{Railway project profile}

The Sichuan-Tibet railway is 1,629-kilometer long. Perched at over 3,000 meters above sea level, and with more than 74 percent of its length running on bridges or in tunnels, the railway will meander through the mountains, the highest of which exceeds 7,000 meters. This railway presents its builders multiple difficulties to overcome, such as avalanches, landslides, earthquakes, terrestrial heat, karst caves and underground streams. The accumulated height it will climb reaches over 14,000 meters. It is believed to be one of the most difficult railway projects to build on Earth. (http://www.chinadaily.com.cn/china/2016-01/30/content_23316800.htm)

We use as a case study the Luding-Xiaohaizi section, which is one of the most difficult parts of this railway. In the study area the highest elevation is 3410 meters. The lowest elevation is 1157 meters. The $\mathrm{X}$ and $\mathrm{Y}$ coordinates 
range from $34515056 \mathrm{~m}$ to $34525766 \mathrm{~m}$ and from $3302264 \mathrm{~m}$ to $3315824 \mathrm{~m}$, respectively. We represent this area using rectangular lattices, in which $357 \times 452$ cells are included. The width of every cell is $30 \mathrm{~m}$. The topography is shown in Fig. 10. The start and end coordinates are S (34520703.2812, 3306974.7485, 1328.200), E (34519022.5530, 3310240.5882, 1665.100). The elevation difference between start and end is $318.9 \mathrm{~m}$, while the airline distance is only $3673.668 \mathrm{~m}$. The natural terrain gradient between the start and end points is $86.8 \%$, greatly exceeding the maximum allowed design gradient of $30 \%$. Hence, the route must be circuitous to overcome the huge elevation difference. The maximum allowable route circuity coefficient $\left(\gamma_{\max }\right)$ is 4.0. Finding the optimizing alignment which satisfies all the constraints is a very difficult task.

The main constraints of this railway are listed in Table2.

\section{Table 2 Main constraints}

\begin{tabular}{|c|l|l|}
\hline \multirow{5}{*}{ Geometric constraints } & minimum radius of curve $\left(R_{\min }\right)$ & $600 \mathrm{~m}$ \\
\cline { 2 - 3 } & maximum gradient $\left(i_{\max }\right)$ & $30 \% \mathrm{o}$ \\
\cline { 2 - 3 } & minimum length of tangent between horizontal curves $\left(L_{I \min }\right)$ & $60 \mathrm{~m}$ \\
\cline { 2 - 3 } & minimum length of horizontal circular curve $\left(L_{C \min }\right)$ & $60 \mathrm{~m}$ \\
\cline { 2 - 3 } Structure constraints & maximum distance between two linked cells $\left(L_{\max }\right)$ & $7000 \mathrm{~m}$ \\
\hline \multirow{2}{*}{ Location constraints } & maximum bridge height $\left(B_{\max }\right)$ & $80 \mathrm{~m}$ \\
\cline { 2 - 3 } & $\begin{array}{l}1 \text { forimum tunnel length }\left(T_{\max }\right) \\
1 \text { environmental sensitive zone } \\
1 \text { river }\end{array}$ & $7000 \mathrm{~m}$ \\
\hline
\end{tabular}

The selected locomotive is SS4, whose weight is 184 tons, and the design train's tonnage is 3,500 tons. The global unit costs are listed in Table 3. The assumed unit costs in special areas will have different values. All these costs are stored in the CGIM.

Table 3 Unit costs

\begin{tabular}{|l|c|l|c|}
\hline \multicolumn{1}{|c|}{ Item } & Cost & \multicolumn{1}{c|}{ Item } & Cost \\
\hline Rail track $(¥ / \mathrm{m})$ & 3,710 & Right of way $\left(¥ / \mathrm{m}^{2}\right)$ & 73.5 \\
\hline Cutting earthwork $\left(¥ / \mathrm{m}^{3}\right)$ & 20 & Filling earthwork $\left(¥ / \mathrm{m}^{3}\right)$ & 18 \\
\hline$(H<50)$ bridge $(¥ / \mathrm{m})$ & 37,800 & $(L \geq 1000 \mathrm{~m})$ Tunnel $(¥ / \mathrm{m})$ & 60,000 \\
\hline$(H \geq 50, L \geq 500 \mathrm{~m})$ bridge $(¥ / \mathrm{m})$ & 58,800 & $(L \geq 400 \mathrm{~m})$ Tunnel $(¥ / \mathrm{m})$ & 56,000 \\
\hline$(H \geq 50, L<500 \mathrm{~m})$ bridge $(¥ / \mathrm{m})$ & 48,000 & $(L<400 \mathrm{~m})$ tunnel $(¥ / \mathrm{m})$ & 54,000 \\
\hline One abutment $(¥)$ & 100,000 & One tunnel portal $(¥)$ & 150,000 \\
\hline $\begin{array}{l}\text { Penalty cost for environmentally } \\
\text { sensitive zone }\left(¥ / \mathrm{m}^{2}\right)\end{array}$ & 500 & Capital recovery factor $\Delta$ & 0.065 \\
\hline
\end{tabular}




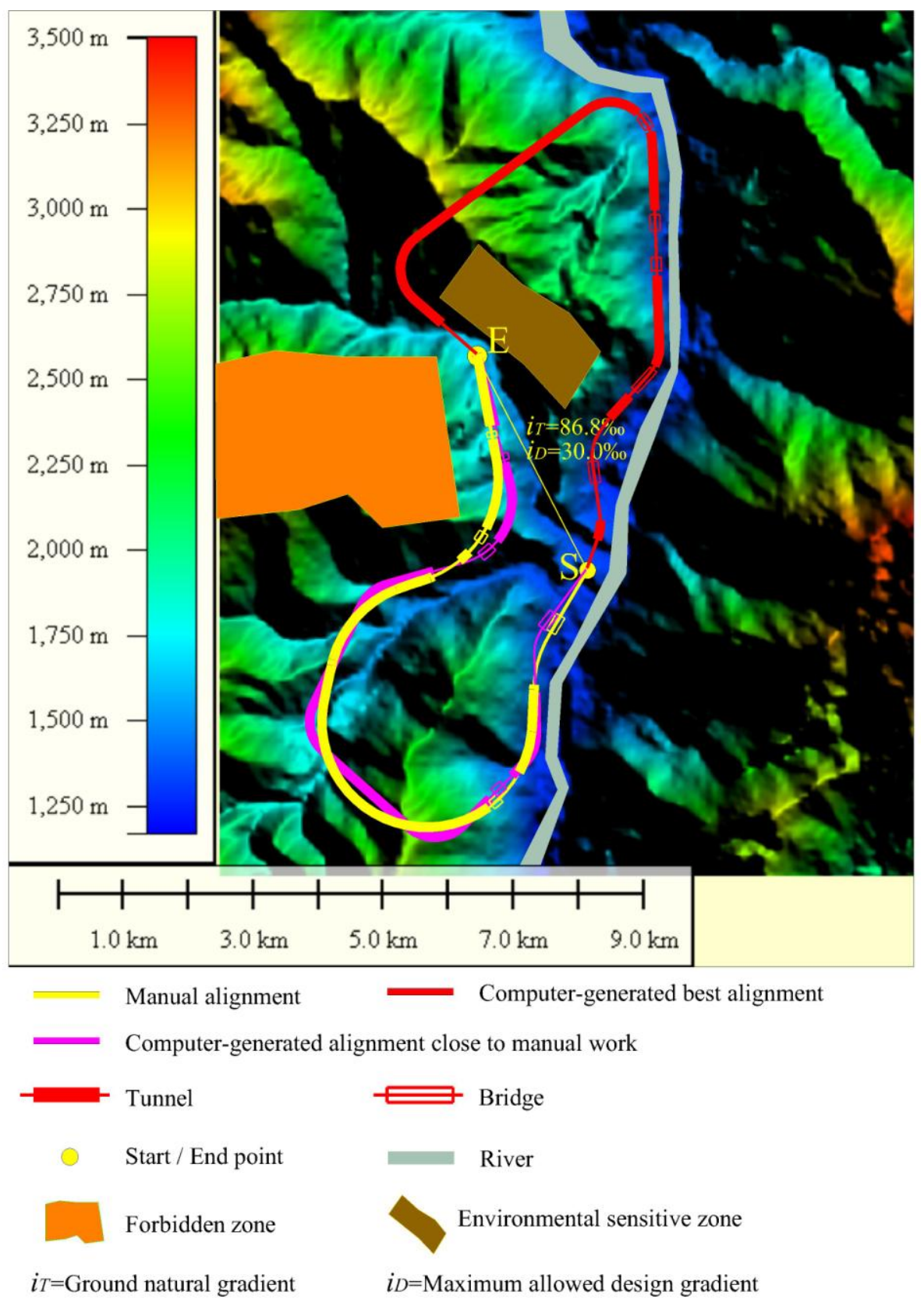

Fig. 10. Topography and alignments in the study area

\subsection{Optimization results}

The program runs on the HP Z600 workstation (Intel Xeon E5506 2.13 G processor, 4GB RAM, 500GB Hard disk). The elapsed time for scanning is 1,653 seconds and 24 paths are generated. All the paths overcome the huge elevation difference and satisfy other geometric constraints, structures constraints, and locations constraints. The paths are sorted by their costs. We choose some representative paths, which include the one close to the manually developed alignment designed by experienced designers at China Railway Eryuan Engineering Group CO.LTD, and fit them to railway alignments (Fig. 10).

Finally, we compare the computed best alignment with the experienced designers' best manual solution, whose results are shown in Fig. 11 and Table 4. The computer-generated best alignment is shorter and has fewer long tunnels, but longer bridges. The comprehensive cost of the manually designed alignment can be reduced by about $9.6 \%$. These results show that the proposed method can find various promising alignments which satisfy multiple constraints and considerably improve upon the alignments determined by skilled and experienced human designers. 
Table 4 Computer-generated best alignment compared with manual work

\begin{tabular}{lll}
\hline index & manual work & $\begin{array}{l}\text { computer-generated } \\
\text { best alignment }\end{array}$ \\
\hline Length/ m & 14,400 & 13,826 \\
Right of way/ $\mathrm{m}^{2}$ & 129,299 & 135,628 \\
Embankment volume $/ \mathrm{m}^{3}$ & 265,679 & 210,735 \\
Excavated volume / ${ }^{3}$ & 355,257 & 426,384 \\
$(H \geq 50 \mathrm{~m})$ Bridge $/ \mathrm{Number}-\mathrm{m}$ & $/$ & $/$ \\
$(H<50 \mathrm{~m})$ Bridge $/ \mathrm{Number}-\mathrm{m}$ & $5-723$ & $5-1,164$ \\
$(L \geq 1000 \mathrm{~m})$ Tunnel $/ \mathrm{Number}-\mathrm{m}$ & $4-10,651$ & $3-8,399$ \\
$(L \geq 400 \mathrm{~m})$ Tunnel/Number-m & $/$ & $1-571$ \\
$(L<400 \mathrm{~m})$ Short Tunnel/Number-m & $1-154$ & $1-316$ \\
Total construction costs / million $¥$ & 752.020 & 673.063 \\
Annual construction costs $(\Delta=0.065) /$ million $¥$ & 48.881 & 43.749 \\
Annual operating cost / million $¥$ & 7.483 & 7.194 \\
Annual comprehensive cost / million $¥$ & 56.364 & 50.943 \\
Annual comprehensive cost saving / million $¥$ & $/$ & 5.421 \\
Ratio of annual comprehensive cost saving & $/$ & $9.6 \%(5.421 / 56.364)$ \\
\hline
\end{tabular}

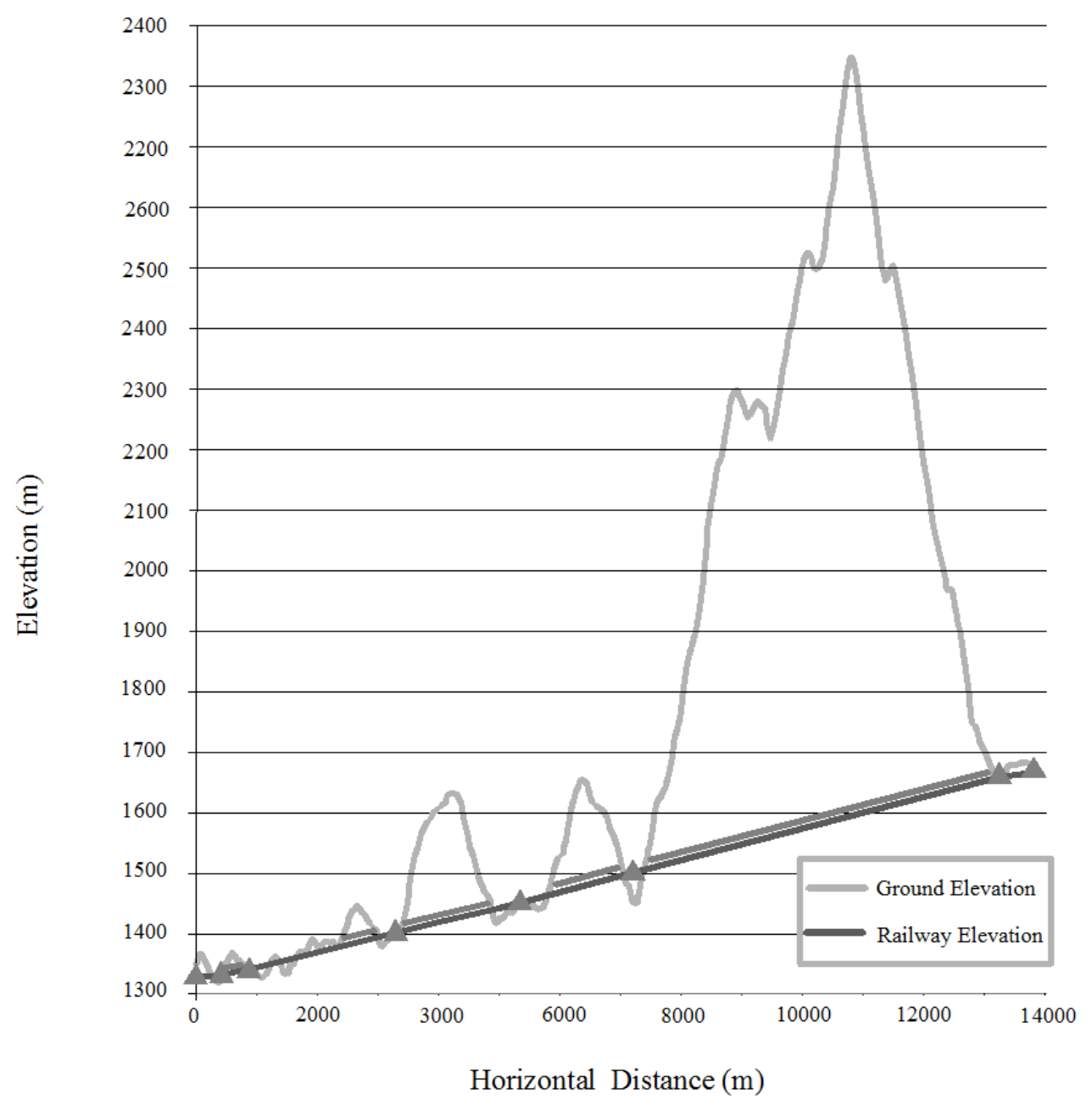

a. Computer-generated vertical alignment 


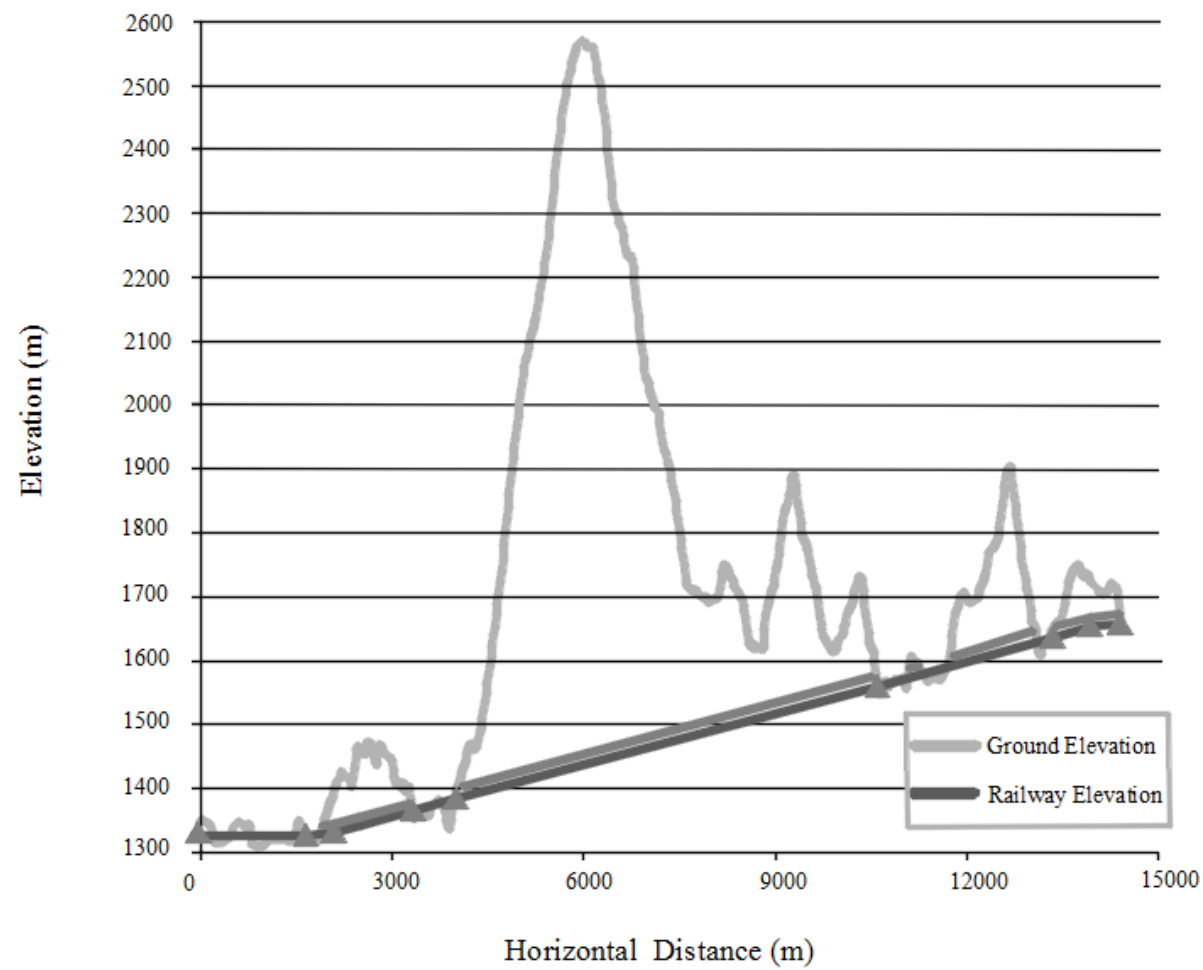

b. Manual vertical alignment

Fig. 11. Vertical alignments

\section{Conclusions}

In this study, a method is proposed for optimizing railway 3D alignment while satisfying multiple constraints in mountainous areas, where the natural terrain gradient between the start and end points greatly exceeds the maximum allowed design gradient. A comprehensive geographic information model is developed to store and manage all the needed information (such as topography, soil conditions, forbidden areas, and unit costs for earthwork, bridges, tunnels and right of way) for the path searching process. Methods for computing the costs of links between cell pairs and satisfying multiple constraints are developed. An adaptive neighboring mask and bidirectional scanning strategy are proposed to improve the success rate of generating path satisfied all the constraints in the mountains. Lastly, the paths are refined into the final alignments. The effectiveness of the algorithm is verified with a real-world case study.

The main improvements provided by this method can be summarized as follows:

(1) This method can find promising alternatives that satisfy multiple constraints in mountainous areas whose natural terrain gradient greatly exceeds the maximum allowed design gradient. This is very difficult for previous cutting planes model approaches since their cutting planes are hard to preset appropriately.

(2) Compared with previous DT methods (De Smith, 2006), more complete constraints, including geometric constraints, structure constraints and location constraints are considered and satisfied, whereas only the slope constraint was considered in previous method.

(3) The dynamic adaptive neighborhood mask is proposed to help satisfy multiple constraints in the scanning, whereas a static mask was employed in the previous DT model.

(4) To generate various alignment alternatives, the bi-directional search strategy is proposed, whereas the single direction search employed by the previous DT model can only generate one alternative.

(5) The model has been applied to a real-world problem and its results are compared to the alignment determined through the experienced designers' manual work. The results show that this method is effective in generating alignments, while satisfying multiple constraints. The alignments can be further refined and optimized in the second stage. 


\section{Acknowledgements}

This work was partially funded by National Science Foundation China (NSFC) with award number 51378512 and Hunan Open Fund for University Innovation Platform, China number 12K007. The authors are very grateful to Doctor M. J. De Smith from the University College London, and to Guangchang Hu and Jianping Hu from China Railway Eryuan Engineering Group CO.LTD. They kindly provided some good suggestions and real cases for this study. The authors are also very grateful to two anonymous reviewers for their very valuable suggestions.

\section{References}

Abramson, M.A., Audet, C., Couture, G., Dennis, Jr., J.E., Le Digabel, S., Tribes, C., 2016. The NOMAD project. Software available at http://www.gerad.ca/nomad. Accessed on April 2.

Athanassoulis, G.C., Calogero, V., 1973. Optimal location of a new highway from A to B: A computer technique for route planning. In: PTRC Seminar Proceedings on Cost Models and Optimization in Highways (Session L9), London.

Audet, C., Dennis, Jr., J.E, 2006. Mesh adaptive direct search algorithms for constrained optimization. SIAM Journal on Optimization, 17(1), 188-217.

Audet, C., Le Digabel, S., Tribes, C., 2009. NOMAD user guide. Technical Report G-2009-37, Les cahiers du GERAD.

Beristain, A., Grana, M., 2010. Pruning algorithm for voronoi skeletons. Electronics Letters 46(1), 39-41.

Chapra, S.C., Canale, R.P., 2006. Numerical Methods for Engineers. McGraw-Hill, New York.

Chew, E.P., Goh, C.J., Fwa, T.F., 1989. Simultaneous optimization of horizontal and vertical alignments for highways. Transportation Research Part B Methodological 23 (5), 315-329.

Cheng, J.F., Lee, Y., 2006. Model for three-dimensional highway alignment. Journal of Transportation Engineering - ASCE 132 (12), 913-920.

China Railway First Survey and Design Institute Group LTD., 1999. China Railway Engineering Design Manual-Alignment. China Railway Press. Beijing.

De Smith, M.J., 2006. Determination of gradient and curvature constrained optimal paths. Computer-Aided Civil and Infrastructure Engineering 21 (1), 24-38.

Easa, S.M., 1988. Selection of roadway grades that minimize earthwork cost using linear programming. Transportation Research Part A Policy \& Practice 22 (2), 121-136.

Easa, S.M., Mehmood, A., 2008. Optimizing design of highway horizontal alignments: new substantive safety approach. Computer-Aided Civil and Infrastructure Engineering 23 (7), 560-573.

Fwa, T.F., 1989. Highway vertical alignment analysis by dynamic programming. In: Transportation Research Record: Journal of the Transportation Research Board, No. 1239, Transportation Research Board of National Academies, Washington, DC, pp. 1-9.

Goh, C.J., Chew, E.P., Fwa, T.F., 1988. Discrete and continuous models for computation of optimal vertical highway alignment. Transportation Research Part B Methodological 22 (6), 399-409.

Hay, W.W., 1982. Railroad Engineering, John Wiley \& Sons.

Hayman, R.W., 1970. Optimization of vertical alignment for highways through mathematical programming. Highway Research Record 306, 1-9.

Hirpa, D., Hare, W., Lucet, Y., Pushak, Y., Tesfamariam, S., 2016. A bi-objective optimization framework for three-dimensional road alignment design. Transportation Research Part C Emerging Technologies 65, 61-78.

Hogan, J.D., 1973. Experience with OPTLOC: optimum location of highway by computer. In: PTRC Seminar Proceedings on Cost Models and Optimization in Highways (Session L10), London.

Howard, B.E., Bramnick, Z., Shaw, J.F.B., 1968. Optimum curvature principle in highway routing. Journal of the Highway Division - ASCE 94 (HW1), 61-82.

Li, Y. Palden, N. 2016, Sichuan-Tibet railway work picks up speed, China Daily, viewed 2 April, http://www.chinadaily.com.cn/china/2016-01/30/content_23316800.htm.

Jha, M.K., Schonfeld, P., 2004. A highway alignment optimization model using geographic information systems. Transportation Research Part A Policy \& Practice 38(6), 455-481.

Jha, M.K., Schonfeld, P., Samanta, S., 2007. Optimizing rail transit routes with genetic algorithms and geographic information system. Journal of Urban Planning and Development 133(3), 161-171. 
Jong, J.-C., 1998. Optimizing Highway Alignments with Genetic Algorithms. Ph.D. dissertation, University of Maryland, College Park.

Jong, J.-C. and Schonfeld, P., 2003. An evolutionary model for simultaneously optimizing three-dimensional highway alignments, Transportation Research Part B Methodological 37(2), 107-128.

Kang, M.-W., Schonfeld, P., and Yang, N., 2009. Prescreening and Repairing in a Genetic Algorithm for Highway Alignment Optimization, Computer-Aided Civil and Infrastructure Engineering 24(2), 109-119.

Kang, M.-W., Yang, N., Schonfeld, P., Jha, M.K., 2010. Bilevel highway route optimization. In: Transportation Research Record: Journal of the Transportation Research Board, No. 2197, Transportation Research Board of National Academies, Washington DC, 107-117.

Kang, M.-W., Jha, M.K., Schonfeld, P., 2012. Applicability of highway alignment optimization models. Transportation Research Part C Emerging Technologies 21(1), 257-286.

Kim, E., Jha, M.K., Son, B., 2005. Improving the computational efficiency of highway alignment optimization models through a stepwise genetic algorithms approach. Transportation Research Part B Methodological 39(4), 339-360.

Kim, E., Jha, M.K., Schonfeld, P., Kim, H.-S., 2007. Highway alignment optimization incorporating bridges and tunnels. Journal of Transportation Engineering-ASCE 133(2), 71-81.

Lai, X. and Schonfeld, P., 2010. Optimizing rail transit alignments connecting multiple major stations, annual TRB Meeting paper 10-2837.

Lai, X. and Schonfeld, P., 2012. Optimization of rail transit alignments considering vehicle dynamics, Transportation Research Record 2275, Transportation Research Board of National Academies, Washington DC, 77-87.

Lai, X. and Schonfeld, P., 2016. Concurrent optimization of rail transit alignment and stations, Urban Rail Transit 2(1), 1-15.

Lee, Y., Tsou, Y.-R., Liu, H.-L., 2009. Optimization method for highway horizontal alignment design. Journal of Transportation Engineering - ASCE 135 (4), 217-224.

Li, W., Pu, H, Zhao H.-F., 2013. Approach for optimizing 3D highway alignments based on two-stage dynamic programming. Journal of Software 8 (11), 2967-2973.

Li, W., 2014. Research and application for key technologies of digitalizing railway alignment design. Ph.D. dissertation. Central South University, Changsha, China.

Liu, Y.-H., Zhao, Q.-J., 2010. An improved watershed algorithm based on multi-scale gradient and distance transformation. In: Proceedings of the International Conference on Image and Signal Processing. Los Alamitos, pp. 3750-3754.

Mandow, L., Perez-de-la-Cruz, J.L., 2004. Sindi: an intelligent assistant for highway design. Expert Systems with Applications 27 (4), 635-644.

Mondal, S., Lucet, Y., Hare, W., 2015. Optimizing horizontal alignment of roads in a specified corridor. Computers \& Operations Research 64, 130-138.

Murchland, J.D., 1973. Methods of vertical profile optimisation for an improvement to an existing road. In: PTRC Seminar Proceedings on Cost Models and Optimisation in Highways (Session L12), London.

Nicholson, A.J., Elms, D.G., Williman, A., 1976. A variational approach to optimal route location. Highway Engineers 23, 22-25.

OECD, 1973. Optimization of Road Alignment by the Use of Computers. Organization of Economic Cooperation and Development, Paris.

Parker, N.A., 1977. Rural highway route corridor selection. Transportation Planning and Technology 3, 247-256.

Pushak, Y., Hare, W., Lucet, Y., 2016. Multiple-path selection for new highway alignments using discrete algorithms. European Journal of Operational Research 248, 415-427.

Puy Huarte, J., 1973. Optimisation and automatic design of highway profiles. In: PTRC Seminar Proceedings on Cost Models \& Optimisation in Highways (Session L13), London.

ReVelle, C.S., Whitlatch, E.E., Wright, J.R., 1997. Civil and Environmental Systems Engineering. Prentice Hall, New Jersey.

Robinson, R., 1973. Automatic design of the road vertical alignment, In: PTRC Seminar Proceedings on Cost Models and Optimisation in Highways (SessionL19), London.

Rosenfeld, A., Pfaltz, J.L., 1966. Sequential operations in digital picture processing. Journal of the ACM 13 (4), 471-484. 
Shafahi, Y., Bagherian, M., 2013. A customized particle swarm method to solve highway alignment optimization problem. Computer-Aided Civil and Infrastructure Engineering 28(1), 52-67.

Shaw, J.F.B., Howard, B.E., 1981. Comparison of two integration methods in transportation routing. In: Transportation Research Record: Journal of the Transportation Research Board, No. 806, Transportation Research Board of National Academies, Washington, DC, pp. 8-13.

Shaw, J.F.B., Howard, B.E., 1982. Expressway route optimization by OCP. Journal of Transportation Engineering - ASCE 108 (TE3), 227-243.

Shih, F. Y., Wu Y. T., 2004. Three-dimensional euclidean distance transformation and its application to shortest path planning. Pattern Recognition, 37(1), 79-92.

Samanta, S, Jha, M.K., 2011. Modeling a rail transit alignment considering different objectives. Transportation Research Part A Policy \& Practice, 45(1), 31-45.

Thomson, N.R., Sykes, J.F., 1988. Route selection through a dynamic ice field using the maximum principle. Transportation Research Part B Methodological 22 (5), 339-356.

Trietsch, D., 1987a. A family of methods for preliminary highway alignment. Transportation Science 21 (1), $17-25$.

Trietsch, D., 1987b. Comprehensive design of highway network. Transportation Science 21 (1), 26-35.

Turner, A.K., Miles, R.D., 1971. A computer-assisted method of regional route location. Highway Research Record 348, 1-15.

Wan, F.Y.M., 1995. Introduction to the Calculus of Variations and its Applications. Chapman \& Hall, New York.

Wright, P. H., 1996. Highway Engineering, John Wiley \&Sons, New York, ISBN-13: 978-0471003151

Yang, N., Kang, M.-W., Schonfeld, P., and Jha, M.K., 2014. Multiple objective optimization of highway alignments incorporating preference information, Transportation Research Part C Emerging Technologies 40, $36-48$. 
Set start cell as target, generate distance image $\mathrm{DT}_{\mathrm{S}}$

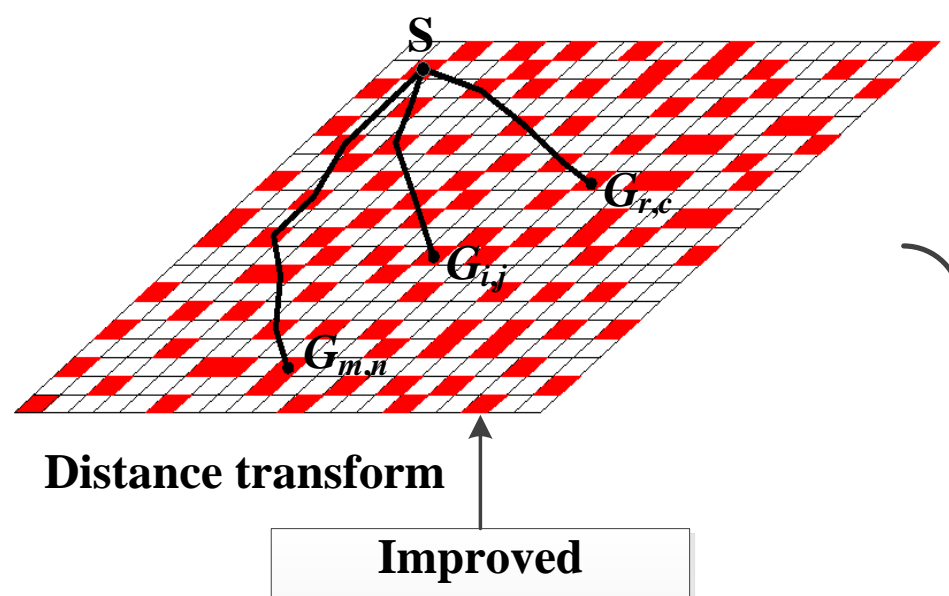

distance transform algorithm

Distance transform

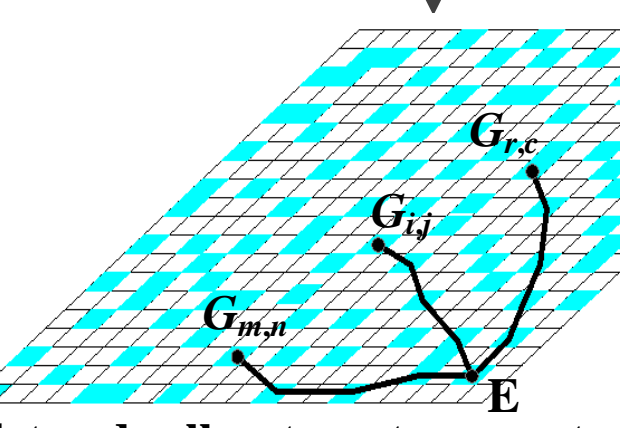

Set end cell as target, generate distance image $\mathrm{DT}_{\mathrm{E}}$

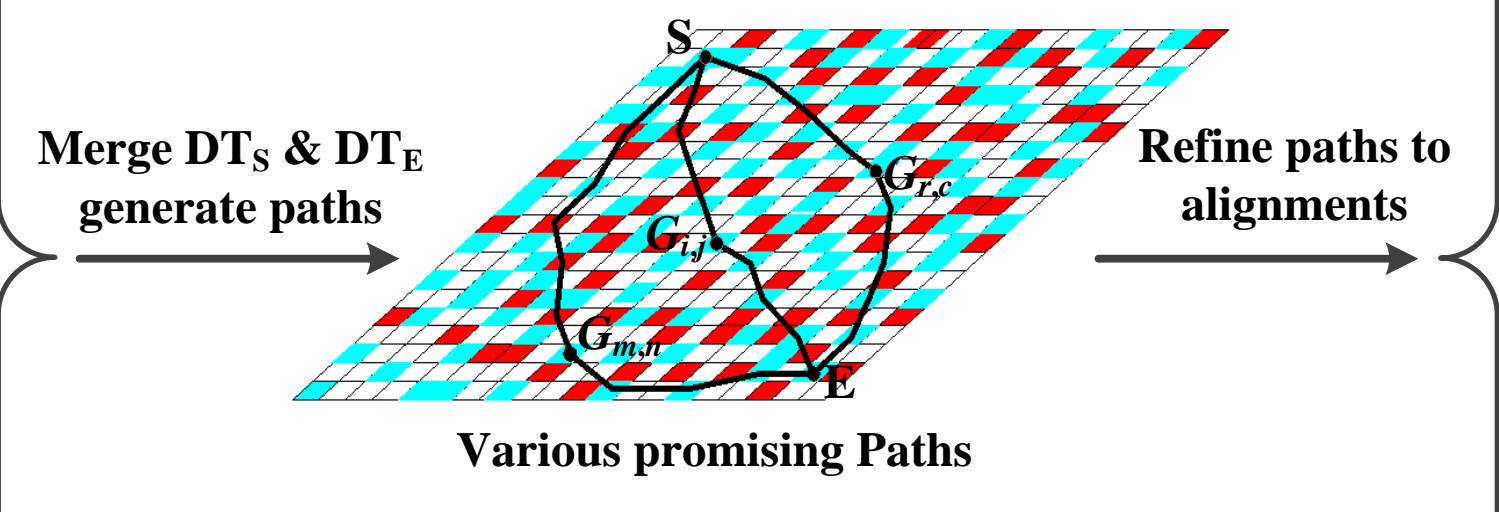

Various promising Paths

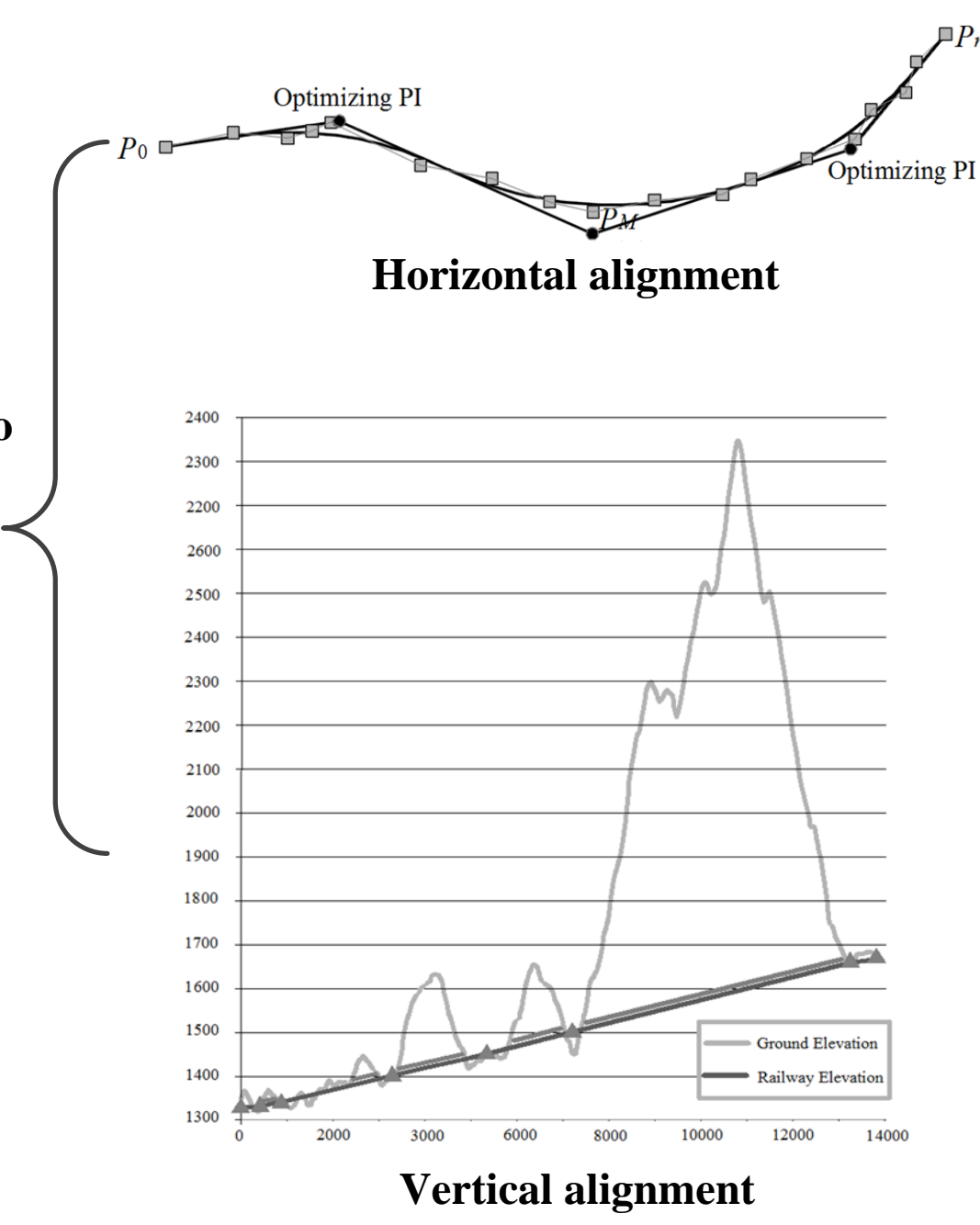

